\title{
The Curious Case of Design Thinking in Museums
}

\author{
Ileana Maris \\ University of Amsterdam \\ Plantage Muidergracht 12 \\ 1018 TV Amsterdam \\ The Netherlands \\ i.maris@uva.nl
}

\author{
Ard Huizing \\ University of Amsterdam \\ Plantage Muidergracht 12 \\ 1018 TV Amsterdam \\ The Netherlands \\ a.huizing@uva.nI
}

\author{
Wim Bouman \\ University of Amsterdam \\ Plantage Muidergracht 12 \\ 1018 TV Amsterdam \\ The Netherlands \\ w.bouman@gmail.com
}

\author{
Marijke Oosterbroek \\ Amsterdam Museum \\ Kalverstraat 92 \\ 1012 PA Amsterdam \\ The Netherland \\ m.oosterbroek \\ @amsterdammuseum.nl
}

\begin{abstract}
In this paper we examine the controversies that arise when a museum engages in the project of developing a proprietary online community for its employees and the interested public. By developing this new online community and actively participating in it, the museum intends to transform itself from a hierarchical institution into an online and offline meeting place for those interested in the museum and its activities. Yet, not all museum employees are at ease with this ambition. We argue that these controversies arise from a mismatch between traditional, linear ways of designing in a museum and a need for more participative approaches in which the public is welcomed as a knowledgeable partner. We put forward the notion of 'design by drawing things together'. By means of illustrations from the Amsterdam Museum, we explain what this approach entails and how it could be beneficial for the present day city museums and their sociotechnological ambitions.
\end{abstract}

Museum changes. Design thinking. Controversies. Online communities.

\section{INTRODUCTION}

Around the world, many historical city museums are undergoing step changes in their relationships with visitors, in their societal functions and in ways of exhibiting art (see Hein 2000, Skartveit and Goodnow 2010, Odding 2011). The Museum for Art and History in Santa Cruz (USA), for instance, is developing towards an organization that is relevant to different communities in the area, and that encourages participation and discussion in the museum by means of event-centred experiences (Simon 2010). In the Netherlands, Amsterdam Museum is transforming from an institution at the service of Amsterdam's history into one at the service of Amsterdam's story, of its local, national and international community (Amsterdam Museum 2013). In a world of social media and communal forms of organizing, these developments may not be unexpected. Yet, they imply serious questions of organizing, identity and authority for those responsible for the museum's viability and continuity (Odding 2011).

In this paper, we examine the project of redesigning the Amsterdam Museum by looking at the technological, public relations and institutional changes the museum is currently undergoing. Our aim is to bring to light and analyse the many discussions, uncertainties and controversies such changes bring about in a city museum like the Amsterdam Museum. By reflecting on these discussions and controversies, we aim at better understanding the nature of the design thinking behind redefining and transforming a museum. We learned that the design thinking and processes used in museums to program activities and prepare exhibitions - characterised by a top down, linear approach in which curators and other experts decide on the content, form and message to be presented to the public - are no longer sustainable or desirable. When designing a participatory museum, in which interaction and sharing between museum employees and the public is encouraged, a new type of design thinking and approach is needed for the transformation to be authentic. We argue that a change in the approach needs to be made from 'design by drawing' to 'design by drawing things together'. In this paper, based on the Amsterdam Museum example we illustrate what 'design by drawing things together' implies in practice and how it could fit the contemporary museum world and its socio-technological ambitions.

Through our study, we hope to engage the museum community in a vivid discussion on how museums can rethink their design approaches in facing the challenge of encouraging public active involvement and commitment to the museum. Likewise, we want to encourage the exchange of experiences and uncertainties with current museum design approaches and as such advance our practical and theoretical understanding of how museums can respond to and benefit from the socio-technological revolution. 


\section{FROM AMSTERDAM HISTORICAL MUSEUM TO AMSTERDAM MUSEUM}

Since its establishment in 1926 as Amsterdam Historical Museum, the museum has dedicated itself to bringing the history of Amsterdam to life. Its rich collection of over 75.000 objects is being appreciated worldwide. The change of name in 2011, into Amsterdam Museum, reflects the museum's ambition to become part and parcel of the contemporary Amsterdam community in particular and the larger international community interested in the history and story of Amsterdam. As a city museum, it positions itself at the heart of the city of Amsterdam, both geographically in terms of its location as well as socially. The museum aims at being 'a meeting place' for those interested in the past and present story of Amsterdam. By means of activities, events and exhibitions prepared in close collaboration with the local community, the museum's goal is to become the connecting link between the inhabitants of Amsterdam and their city.

To meet these aims, Amsterdam Museum tries to find suitable fresh arrangements in its way of organizing, in its supportive technologies and in its interaction with diverse stakeholders, particularly the public. For facilitating such interactions, the museum engages in various internal and external collaborations to develop online and offline interactive technologies. Central in this process is the museum's collaboration with Mediamatic, a leading Dutch web-design office, to fashion an online community platform as part of the overall transition.

The museum considers that a successful design and implementation of such interactive technologies needs to go together with an encompassing redesign of the museum itself. Designing an outreaching, participatory museum is no longer a matter of drawing sketches, developing them into a product, testing the product and evaluating it. Rather, it becomes a matter of drawing things together - interactive technologies, art objects, public stories - and making them work together. The design process does not need to finish when an exhibition or an event is opened. On the contrary, it needs to be a continuous process, engaging the public further and responding sincerely to their expected and unexpected reactions.

This change in the design approach is not without challenges. What it means to create new online and offline spaces for interaction and collaboration between museum employees and the public, and what the implications are for being a museum, is always under discussion and negotiation. It is these discussions or controversies (Venturini 2010) in designing an open, participatory museum that we observed and traced during our field research.

\section{TRACING CONTROVERIES: METHODS}

Venturini (2010: 261, emphasis in original) argues that "controversies are situations where actors disagree (or better, agree on their disagreement)". A controversy is settled when actors manage to reach a compromise they can live with (Venturini 2010). From our study we learned that engaging in controversies is at the very heart of designing for online and offline interaction and collaboration.

To trace the controversies generated in the redesign of the Amsterdam Museum, we followed Latour's (2005) advice 'to follow the actors themselves'. We conducted in-situ observations of designers at work both in the museum and the web-design office, observing designers sketching, attending meetings among and between museum employees and web-designers and presentations. To make sure that our understandings of what we observed were shared by the designers, at the end of a meeting or during sketching we asked the designers and museum employees to tell us from their point of view what happened during that meeting or what were their thoughts during sketching. Field notes and photos were taken throughout the entire observation period.

The observations were supplemented with 26 semistructured interviews with web-designers - graphic designers, interaction designers, concept developers and museum employees - project managers, social media employees and the director. The interviews were recorded and transcribed verbatim for analysis. Document analysis was employed too, inspecting policy documents written for the museum, design proposals, news articles and blog posts related to the museum's activities, events descriptions and stories and comments posted on the online platform once it was launched.

\section{RETHINKING TODAY'S MUSEUM: FEEDING OFF CONTROVERSIES}

Our study shows that in the Amsterdam Museum design project controversies exist at two interrelated levels: inside the museum, between employees thinking from the perspective of the museum as an institution and those thinking from the perspective of the museum as one actor in a community network; and outside the museum, between the museum, funding agencies, webdesigners and members of the online community. In this paper, we outline three of the many controversies we observed inside the museum.

Controversy 1: On the design approach to be taken: A top-down authoritative design versus a bottom-up participative design

The image of the manager as the solitary mastermind and responsible force behind design is inadequate. Our study shows that designing for interaction and collaboration is a multi-actor undertaking. In order for the design to work, 
museum management and staff, web-designers, members of the online community, funding bodies and so on collectively shape the design process and outcomes. Effective designing is performed in a 'practice net' (Nicolini 2009). Designing is distributed and a shared understanding spreading across the institution and beyond is constantly negotiated. As the manager of the e-culture department of the Amsterdam Museum puts it:

"I see all actors involved in community development (volunteers, colleagues, web-designers) as influencers of the design process".

However, whereas all groups involved are seen as influencing the design process, the degree of influence everybody has is frequently negotiated. These negotiations of influence seem to be shaped by one important discourse: that of responsibility. In both the domain of museums and design, the discourse of responsibility is important in shaping the two practices (Sherman 1994, Marstine 2011). Different actors have different ideas of what responsibility entails, and as such have different perceptions on who are the main designers of the new participatory museum. Also, they have different visions on how designing should be approached.

Thinking from the perspective of the museum as a cultural institution, some employees consider that the museum has an institutional responsibility (cf. Sherman 1994) towards the public. They highlight the museum's duty to offer a high culture environment where people can learn about the history of the city as well as the history and stories of its inhabitants. The Amsterdam Museum's aim is to "bring history to life" and be a "binding element between the inhabitants and their city and among the inhabitants themselves" (Policy document Amsterdam Museum 2020, 13 March 2011). Also, the museum has a great responsibility for the art it curates, in the sense that it has to keep it up to date, in good condition, make it available to the public and translate it into text, audio and video files so that all the layers of the public can appreciate and enjoy it. As described in the Information Policy Plan of Amsterdam Historical Museum 2009-2013 (20 March 2009):

"The Amsterdam Historical Museum has the aim of keeping the history of Amsterdam alive and making it accessible to as broad a public as possible. The museum aims to present the history of Amsterdam through present-day, inspirational and interactive ways, for this making optimal use of the historical collection of the city of Amsterdam, which the museum curates, maintains, researches and selectively expands".

The museum as an institution, represented by the director and the management board, is seen as the responsible designer as policy making regarding the vision of the museum, its identity, its use of technology and role in society is decided at the institutional level. It is argued that for the design process to be effective in achieving its intended goals, it needs to be managed and monitored by visionary people. The design approach to be taken is therefore a top-down one, in which the managerial vision gradually becomes the underlying philosophy in the employees' daily work. As one project manager explained:

"This is a lot of times what happens, we get a new director and he comes with new and fresh ideas. He comes in with a vision and shares that vision with some people in management and if they share that vision, and they did, then it becomes a sort of company vision, a museum vision and that starts being used as a base".

In their design negotiations inside the museum, the director and the management board draw together management philosophies, budgets, museum objects and physical spaces, annual reports, governmental requests and expectations from the museum, and so on to illustrate their design principle: the museum will be able to change into an open and participatory museum only if all the employees come to realize that they need to behave differently. In the words of one manager:

"I think one of the most important things it's getting people to understand what is necessary from the director to the people that work for the safety of the museum, everybody has to learn that they have to be different, behave different to make this work and that's a long term thing. And I try to make it happen, for instance by changing rules and by introducing new practices in the work".

The museum's e-culture department brings to the negotiation table a more bottom-up perspective. They consider that the museum's role is not only an institutional one but also a communal one. In their view, the museum is just one actor in a community network of people and organizations that want to tell the story of Amsterdam. It has a social responsibility (cf. Marstine 2011) to invite people to participate, express their opinions, to bring in their own personal stories about their city. The museum no longer needs to take upon itself the responsibility to "bring history to life" but should see it as a shared responsibility with the public to "tell the story of the city" as lived by its inhabitants.

For the e-culture department, the same shared responsibility needs to be acknowledged and performed inside the museum too. They argue, that in order for the design process to achieve its intended goals, the designing of the new museum needs to involve and be performed by employees at all levels of the organization, and not just the management board. It is considered that if the management does not welcome all the employees, members of the public and other stakeholders in the design process, and does not encourage them to have their say in how they would like the museum to be in the future, the design process will fail. As the e-culture manager puts it:

"This is what is different with this kind of designing, that it is so complex that you can no longer design it at the drawing table. [...] । think that if you make an administrative programme you should build it with the people and not for the people. [...] But this is a new way of working in which you have different responsibilities that need to balance out. With all the groups you sit together and discuss and you realize that things need to be done differently. And this whole 
process I see as designing, actually. It's really working together, otherwise it won't work".

In their design negotiations, the e-culture department employees draw together plans for more interactive ways of working in the museum, social media technologies as potential platforms for interaction, community inspired attitudes of collaboration, examples of museums that were successful and less successful in encouraging collaboration between them and their public, wishes expressed by the public, and so on to illustrate their design principle: "if you design for something social, you should do it in a way that people will flourish", as the e-culture manager put it.

These negotiations are not without implications for the design process. We have seen that the debate inside the museum is one between a top-down versus a bottom-up approach to designing the museum. As such, the larger implication is that related to how the design of the museum will be carried out in practice, in the real life setting of the museum. It is argued that the challenge of changing a traditionally introvert institution into an open, community meeting place lies in that you cannot make interaction and collaboration happen: "The first thing that you need to know is that you can only facilitate. You cannot really make it happen; you can only [...] invite the process to happen.

Key to "inviting the process to happen", it is argued, is to treat everybody as equal partners and appreciate their inputs and knowledge. Only in this way, employees will become more committed to the design goal. Current changes in the ways of working in the museum begin to reflect this design philosophy. For instance, in preparing exhibitions, employees from different departments are encouraged to work together on a project basis, which allows them to work more like a team rather than as individual departments. Online, all employees are encouraged to become members of the online community, to write about their daily work or to engage in conversations with the public by using their own names instead of the museum's name. This makes the interaction with the public more personal. Likewise, the museum organizes monthly meetings with members of the public in which they are encouraged to present their wishes for organizing online and offline events, for the way the platform is designed and organized.

While being put forward as an important and effective design philosophy, equality remains problematic and continually challenged in the museum. This is particularly visible in another controversy that shapes the design process, namely on the future legitimacy of the museum as a cultural institution.

Controversy 2: On the legitimacy of the museum: Museum as an expert system versus museum as a community system

Design challenges, like designing for interaction and participation in a museum, are not matters of fact, but matters of concern (Latour 2005). Always in a state of becoming, they persist in attracting designers' creative imagination. At every stage of the design process, the museum unfolds itself differently to various actors, providing room for debate and improvement. Here too, supporters of the museum as institution view clash in ideas with the proponents of a more community view. The discourses of legitimacy and authority (Kavanagh 1994, Anderson 2004) are the frame in which this controversy is carried out.

For a long time, museums have been seen as important providers of information about historical events and art. Their legitimacy and authority came from the specialized knowledge of their experts, from research and from the uniqueness of their collections. This authority is to a certain extent challenged today as the public itself engages in research, has more sources of information and wants to participate in discussions with museum experts (Anderson 2004, Simon 2010). In the Amsterdam Museum, different employees perceive the legitimacy of the museum in different ways, and have different ideas regarding the type of authority the museum should encourage in the future.

This controversy is strongly visible in the preparations for an exhibition dedicated to the internationally acclaimed Dutch football player Johan Cruijff. Some museum employees had doubts whether the Amsterdam Museum is the right place to talk about a living football player, let alone prepare an exhibition about him. The argument that supported the decision to go ahead with the exhibition, and that will frame it to a certain extent, is that Johan Cruijff can be seen as an embodiment of what the city of Amsterdam is historically known for: creativity, entrepreneurship, free thinking and citizenship. Particular about this exhibition is that it will not be an overview of his life or sport related achievements, which can be read about in the various books and magazines written about Johan Cruijff. Rather, it will offer the story of his encounters with his fans. As such, this will be the first exhibition in the museum that will be prepared by using personal anecdotes and pictures the public posts on the museum's online community, through which they tell the story of their encounter with Johan Cruijff. The museum will also collect personal objects, such as balls or t-shirts that used to belong to Johan Cruijff and that are now in private hands.

Lively discussions are carried out as to who should be the story tellers in the exhibition, the museum or the public, should the best stories be selected by the museum or the public, and most importantly, will the museum's reliability and legitimacy as a cultural institution be questioned in the museum world, if they invite football fans not only to come to the exhibition, but to be involved in its composition as experts? This tension was explained to us by the e-culture manager:

"Art is undisputed, like nobody will ask you why are you going to a museum to see a Rembrandt painting. And in a museum like ours you have to tell more clearly why Johan Cruijff can be in, you are showing 
something that is not true, subjective things. That is of course very disputable. Some people ask whether these stories need to be in the museum or whether it is not too uninteresting for people, or whether it is not too shallow, there are people who say that".

In these discussions, different museum employees draw together ideas on expertise, historical museum objects, interactive technologies, anecdotes, personal objects and pictures sent in by the public, plans for the exhibition, examples of similar exhibitions in other museums and so on to negotiate a design vision for a successful exhibition.

For the supporters of the museum as institution view, the museum through its staff is and should remain the knowledge authority in selecting the most appropriate stories from those posted online, in combining them in such a way that together they represent a coherent story about Johan Cruijff's encounters with his fans. They view the online community platform and other interactive technologies employed in the exhibition as important means to reach and interact with the public, invite them to contribute to the exhibition, and enrich their museum experience (cf. Mancini and Carreras 2010 for a similar argument).

However, in contrast to the museum experts, the public is not seen as having the expert knowledge required to compose a consistent, objective story of Johan Cruijff. As such, it is argued that in the exhibition, the online and offline environments could be interrelated, yet they would remain autonomous. Dissolving the boundaries between the offline exhibition and the online platform would have the danger of transforming the exhibition and in general the entire museum into "a Wikipedia", threatening the museum's legitimacy as the teller of Amsterdam's story. As one project manager explained:

"Online everybody has an opinion, it is very much customer oriented meaning that everybody can contribute their stories. Yet, this does not mean that these stories are the truth, in historical terms, but a general opinion. Objectivity, or searching for objectivity, is one of the tasks of the museum. Here we have curators who are telling a story. They do have personal views but are also trained in telling that story. The internet is lacking that, it's lacking the expert and without this expert, everything would be just a Wikipedia."

This vision is challenged by other employees who no longer believe in the sustained authority and legitimacy of the museum (cf. Anderson 2004). They argue that larger societal changes, brought about by the concurrent spread of social media technologies and democratizing, are changing also the ways in which the public relates to the museum. Like in social media, the public wants to participate in the museum and share their stories (cf. Simon 2010). To accommodate these changes, the museum will have to rethink itself and reconsider its authoritative status (cf. Odding 2011). Yet, this change does not go without the fear of losing legitimacy and the public's interest. This fear was explained to us by the exhibition's project manager:
"We had the vision that the website should be absolutely open. A story that is sent in is automatically shown on the website, it's visible for everybody. Some people were afraid that if we did that, the best stories will already be placed and there won't be any news value when we open the exhibition. So they were afraid that if there was one special story among all those stories, then by placing it already on the website the press would not be interested or less interested, or maybe the audience will be less interested in coming to the museum. I think that is an old fashioned way of thinking because our experiences with the website are that people get more involved by reading stories, they get triggered to donate their own story or put somebody else in contact with the story".

For employees like the exhibition's project manager, the new online community platform is more than a means to collaborate with the public. It represents therefore also the arena where current ways of being a museum and of doing things in the museum and on the web can be challenged by an opiniated, knowledgeable and diverse public. However, it is argued that with such exhibitions, where the public are the experts providing pictures and anecdotes of events in their lives, the museum's legitimacy is not challenged, but transformed to accommodate other views, and other types of expertise. To allow for such a mix of expertise, the museum needs to transform from an educating institution to one in which joint learning with the public is promoted, from a collector of histories to a co-producer of life stories, and from an authority to a host. Otherwise, they argue, the online community will remain separated from the actual museum, as an inauthentic and insincere publicity medium, or as "just another Facebook" as an employee put it. As the e-culture department manager explained:

"If different groups are to work together, they need to feel involved, concerned with the museum. And the museum should encourage that, make it possible that people from the community get access, sometimes literally get access, and that colleagues are open for this. This needs to go through all the layers of the organization and the environment needs to change if it is to work, otherwise it is not a community but an oldfashioned members group."

The controversy on the future legitimacy of the museum has important implications for the design process. We have seen above that this controversy brings to the fore issues of legitimacy and of changing systems of expertise. The larger implication for the design process is related to how the object of designing is defined.

It is argued that if the museum is to succeed in being a sincere and authentic online and offline meeting place between museum experts and the public, the design process should encompass not only the online community platform but the entire organization and its perceptions of the online platform. As such, the design object becomes much broader. It is about creating "a surrounding that works" as the e-culture manager put it, that incorporates both the online and the offline environments. Creating a surrounding that works means attending to employees and public's 
attitudes, organizational aspects and technical aspects. Says the e-culture manager:

"For it to be real and interesting it has to be authentic. It also has to be about the museum so the employees have to adapt to a new situation. But it also means that it has technical implications because you are no longer sending information, but communicating. Employees get a lot more responsibility, they have to respond to the public and be a lot more flexible. And also you have to create new surroundings like the community site, where there is real interaction between the public itself but also between the public and our workers. So that is a technical aspect but also an organizational aspect".

As museum designers begin to attend to the employees' own attitudes, hierarchies and current ways of working, another sharp controversy is ignited in the museum, namely that on the agency of objects.

\section{Controversy 3: On object agency: Objects speak for themselves versus Objects are stories too}

An integral part of any museum in the world, one that defines to some extent their identity and status, is its collection of art and historical objects (Hein 2000). In designing for interaction and collaboration in the context of the museum, the collection plays an important role too. However, as we have seen with the exhibition on Johan Cruijff, the museum's art and historical objects are not the only objects to matter in the design process. Other, more personal objects and interactive technologies begin to show their influence too.

Yet, which objects matter and how they matter in the designing of the new, participatory museum is also an issue frequently under debate. Employees draw on the discourses of objectivity and subjectivity to direct these negotiations. These two discourses are clashing in other museums too (Genoways 2006, Odding 2011). It is argued that whereas museums are welcoming visitors to engage in exhibitions, curators and other museum employees are still uncomfortable with their own and their visitors' subjectivities in preparing these exhibitions, and so they give priority to the museum's historical objects and the institutionalized knowledge they embody (McLean 2007, Simon 2010).

In the Amsterdam Museum, the design visions of different employees seem to be guided by different objects, based on the values they give to objectivity and subjectivity in the museum. In their design negotiations, different museum employees draw together historical objects, established ways of exhibiting art, online and offline interactive technologies, anecdotes, pictures and objects donated by the public, examples from other museums and so on to negotiate a design vision on how to accommodate the diversity of objects and stories the museum collects.

Some employees' visions of the new museum are still focused on the collection, regarding it crucial for telling the story of Amsterdam. The objects in the collection are seen as "the real deal" for which visitors come to the museum in the first place, as one employee explained. They are the objects that embody formalized, trustworthy knowledge about the past and as such they can be used by the museum to tell the story in as an objective way as possible. As such, they argue that in designing of the museum attention should be paid to bringing the whole museum's collection to the fore and making it all available to the public.

A first step was the development of an online, digital depot to contain pictures of and information about the objects in the collection. The underlying philosophy of putting the entire museum's collection online is that the museum's aim is no longer to give information to a homogeneous public, but to share knowledge with a public with different interests in the collection. Visitors are encouraged to leave their comments on the objects they view. Also online, in the community, different curators write daily blog posts about a particular object from the collection, highlighting its background and significance for the day. Here too, online visitors can leave their comments on the posts they read. However, the relationship between the online and offline spaces of presenting the collection still remains a complicated one for many employees. It is argued that while the internet is helpful in learning more about the collection, it can never replace the experience of visiting the collection in the physical environment of the museum. As one employee explained:

"For those already working here for thirty years, it will take some time for the online platform to be really integrated in their way of thinking because they will experience it more like "you have to come to the museum and experience it otherwise". And I agree, to look at an object from close by is something totally different from experiencing it on the internet. I mean, then you get a zap culture and if you see a seventeenth century object, it moves you in a way totally different than internet can do. So you need the real deal, but you also need the internet to make sure that they experience the real deal".

Another solution was offered offline. It consists in redesigning and reallocating the exhibition spaces to accommodate a more flexible way of exhibiting the collection. A part of the main exhibition space is reserved for the Amsterdam DNA exhibition. Targeted primarily for tourists, the exhibition is designed to combine a rich assemblage of historical objects and multimedia technologies such as audio and video screens. This assemblage is aimed at telling the story of Amsterdam in 45 minutes. The exhibition is extended online also. It has its own website, where visitors can go to for more personalized information about the video and audio choices they made during the exhibition. The remaining part is reserved for the permanent exhibition of historical and art objects. This part is less interactive and more collection based, offering more information about the historical background of the city. In the temporary exhibitions, the same mix of historical objects and interactive offline and online technologies is wished for. 
However, it is argued that in exhibitions such technologies should not overwhelm the historical objects. Interactive technologies are seen as adding an extra layer to the exhibited objects, making the story these objects tell stronger. Yet, the historical objects still remain the most important ones. Some employees explained that the power of these objects is that they are able to speak for themselves, to tell a story. Just by looking at a historical object, you are able to understand something significant about the past. As a project manager explained:

"I mean objects tell the story, and objects are one of the most important things we have so don't neglect that. And sometimes you have more objects and less interaction and sometimes you have a bit more interaction and less objects, it depends. [...] It's a couple of ingredients that decides but in general you can say that the new generation of audience that we are having now and that we will continue with in this century is more and more interactive and more audiovisual. But they still come to see the objects from the $17^{\text {th }}$ century, that will stay as a red line through everything.

Other employees agree that the assemblage of historical objects and interactive technologies offer a richer story of Amsterdam than either one could do by itself. However, they argue that this story is still one told by the museum only, a researched, formalized story that visitors listen to. Their vision of the museum is one in which the public gets involved with the museum and its objects in a more personal way. Visitors need to be given the space to say what they like and do not like, to offer their lived experiences of the city and to discuss with other visitors and employees about issues that matter to them in regard to their city. The new museum needs to be a place where personal stories are given space, either online or offline, to develop alongside the official, museum story. In this way, the museum's historical objects will be able to unfold in ever richer representations of Amsterdam's past and present. As the manager of the e-culture department puts it:

"If you want the past to be in the service of the present, then you have to come up with means that people feel attached to. For that you need not only physical objects but also you need to take care that the objects would unfold and thus become more interesting by attaching to them more understandable stories for people, and going so far that people can bring in their own stories."

Encouraging the public to bring in their own stories and objects in the museum has yet another effect: it challenges the current ways of being a museum. It is argued that if the museum is to become more of a meeting place where different people can talk about Amsterdam, "being Amsterdam will be more important than the objects the museum has", as one employee put it. Designing an open, participatory museum requires therefore the design of a space where different objects, such as historical objects, interactive technologies, personal anecdotes and objects, can unfold so that they together can tell the story of Amsterdam.
The implication of this controversy for the design process is significant. We have seen that this controversy brings to the fore issues of museum's scope and role in society in general. But what is seen as the most practical implication is on how the success of the design itself will be evaluated. Some employees, thinking more from the institutional perspective, argue that the successful redesign of the museum into one that encourages interaction online and offline should lead to a significant increase in actual public visits in the museum. A museum employee explained the importance of having facts and figures of the effect of online interaction on the actual museum visits:

"If people read the story online about the history of Amsterdam that's all fine but I want to know how many people that do that actually go to the museum. So I want to know how we use the medium, the interaction, what the results are, if people visit the museum more had there not been interaction. [...] I mean, if people don't visit the museum, we don't get any income and then the government will say "hey you are not doing a good job". So basically, we need people to come and experience the museum."

However, while other employees agree that an increased visit in the museum is desired, they do not see this as the only important evaluation. For them, the number of people that register and are active participants online is also a very important success factor. Likewise, the amount and quality of online discussions among the public and between the public and museum employees is very important also. And finally, how committed the public and museum employees feel to the museum and its activities, how attached they are to the story the museum is telling, together with them, and how attached they are to the city, are also important. A committed public is helping the museum not only by visiting its exhibitions, but also by donating, by volunteering in organizing events or in helping conserving the museum's collection still found in the depot.

\section{DESIGN THINKING - THINKING OF WHAT MAKES THE DESIGN WORK}

In our research we aimed at understanding the nature of design thinking in designing new organizational forms for the Amsterdam Museum. To trace design thinking in action we examined three design controversies or moments where all actors in the design process negotiate the way the museum should proceed to improve.

The importance of these controversies is that they constitute the forum where existing practices are challenged and their adequacy for the future is questioned (Odding 2011). Controversies challenge everybody to think about the museum in a new way. Employees are made to reflect on their responsibilities, authorities and legitimacies. As such, it is through these controversies that the basis of the new, interactive museum begins to take shape. What we see at the moment is a hybrid form of being a museum, where both institutional and community oriented ways of thinking and working are present at the same time (Odding 2011). 
We hold that design thinking becomes material at the moment when design is practiced in terms of drawing things together. Drawing things together, in a highly interactive, fluid and chaotic session such as the ones we studied, encourages designers to explore the same design issue from different perspectives, in different situations. They afford for creative discoveries that neither designer alone or in a team could think of (Lawson 2006). Nobody knows for sure what the Amsterdam Museum, like other city museums, will be in the future, or what their role will be in society (Simon 2010). Yet, these museums know what they would like to achieve and engage all their employees, the public and other stakeholders in vivid discussions. Designing for interaction and collaboration reflects a thinking about how to draw different human and non-human actors together and allow them to unfold to their full potential.

Designing a museum where a close interaction and collaboration between employees and the public can take place is an instance of what Jones (1992) calls 'designing without a product'. It is different from designing a web page, a chair or a house; designing without a product requires a larger, encompassing focus on creating not tools for action, but the possibilities for action itself (Wilson et al. 2004). In such design projects, it is never known from the start what the outcome will be, whether action or interaction will take place and what will be the full consequences. Knowing how to design for possibilities of action or interaction in the particular context of the Amsterdam Museum is not a matter of applying testable, scientific design theories. Rather, it is a matter of feeling, of a 'designerly way of knowing' (Cross 2001), of a situated knowing and thinking in practice. Such implicit and situated knowing and thinking in practice is hard to codify, if at all. Yet, it can be made explicit through concrete examples, studies and discussions. We hope our study will stimulate the museum employees' reflections on their work and as such keep these discussions going.

\section{REFERENCES}

Anderson, G. (Ed.) (2004) Reinventing the museum: Philosophical and contemporary perspectives on the paradigm shift. AltaMira Press: Walnut Creek.

Barden, M. (2011) Tate membership and customer relationships management. Presentation given at Kom Je Ook 11 Symposium, 29 March 2012, Amsterdam.

Buchanan, R. (1992) Wicked problems in design. Design Issues, 8(2), pp. 5-21.

Cross, N. (2001) Designerly ways of knowing: Design discipline versus design science. Design Issues, 17(3), pp. 49-55.

Genoways, H. (2006) Museum philosophy for the twentyfirst century. AltaMira Press: Lanham.
Hein, H. (2000) The museum in transition: A philosophical perspective. Smithsonian Institution Press: Washington DC.

Jones, J.C. (1992) Design methods. John Wiley \& Sons: New York.

Kavanagh, G. (Ed.) (1994) Museum provision and professionalism. Routledge: London.

Latour, B. (2005) Reassembling the social. An introduction to actor-network-theory. Oxford: Oxford University Press.

Lawson, B. (2006) How designers think: The design process demystified. Elsevier Architectural Press: Amsterdam.

Mancini, F. and Carreras, C. (2010) Techno-society at the service of memory institutions: Web 2.0 in museums. Catalan Journal of Communication and Cultural Studies, 2(1), pp. 59-76.

Marstine, J. (Ed.) (2011) The Routledge companion to museum ethic: Refining ethics for the twenty-first century museum. Routledge: New York.

McLean, K. (2007) Do museum exhibitions have a future? Curator, 50(1), pp. 109-122.

Nicolini, D. (2009) Zooming in and out: studying practices by switching theoretical lenses and trailing connections. Organization Studies, 30(12), pp. 1391-1418.

Odding, A. (2011) Het disruptive museum [The disruptive museum]. O dubble d: The Hague.

Schön, D. (1983) The reflective practitioner. Basic Books: New York.

Sherman, D. (1994) Museum culture: Histories, discourses, spectacles. University of Minnesota Press: Minneapolis.

Simon, N. (2010) The participatory museum. Museum2.0: Santa Cruz.

Skartveit, H. and Goodnow, K. (Eds.) (2010) Changes in museum practice. New media, refugees and participation. Museum of London and Berghahn Books.

Venturini, T., (2010) Diving in magma: how to explore controversies with actor-network theory. Public Understanding of Science, 19(3), pp. 258-273.

Wilson, B., Ludwig-Hardman, S., Thornam, C. and Dunlap, J. (2004) Bounded community: designing and facilitating learning communities in formal courses. The International Review of Research in Open and Distance Learning, 5(3), pp. 1-22.

\section{Policy documents:}

Amsterdam Museum (2011) Amsterdam Museum 2020.

Amsterdam Museum (2009) Informatiebeleidsplan AHM 2009-2013.

\section{Online sources:}

Amsterdam Museum: www.amsterdammuseum.nl 